\title{
Transferrin microheterogeneity in rheumatoid arthritis
}

\section{Relation with disease activity and anemia of chronic disease}

\author{
R. A. Feelders ${ }^{1}$, G. Vreugdenhil ${ }^{2}$, G. de Jong ${ }^{3}$, A. J. G. Swaak ${ }^{4,5}$, and H. G. van Eijk ${ }^{1}$ \\ 1 Department of Chemical Pathology, Erasmus University, Rotterdam, The Netherlands \\ 2 Department of Internal Medicine, Division of Haematology, University Hospital, Nijmegen, The Netherlands \\ ${ }^{3}$ Department of Internal Medicine II, Academic Hospital, Rotterdam, The Netherlands \\ ${ }^{4}$ Department of Rheumatology, Dr. Daniel den Hoed Clinic, Groene Hilledijk 301, NL-3075 EA Rotterdam, The Netherlands \\ ${ }^{5}$ Central Laboratory of the Netherlands Red Cross Blood Transfusion Service, Amsterdam, The Netherlands
}

Received April 2, 1992/Accepted July 17, 1992

Summary. We studied the relation between disease activity in rheumatoid arthritis (RA) and the microheterogeneity of transferrin. Using crossed immuno isoelectric focusing, transferrin microheterogeneity patterns were analyzed in sera of healthy individuals, nonanemic RA patients, iron deficient RA patients and RA patients with the anemia of chronic disease (ACD). In all RA groups a significant shift in the microheterogeneity pattern was observed, reflecting increased synthesis of transferrins with highly branched glycan chains. Increased disease activity correlated with both the induction of ACD and the change in transferrin glycosylation, which was, therefore, most pronounced in ACD. Generally, an increased synthesis of glycoproteins is accompanied by alterations in their glycosylation pattern. Since transferrin is a negative acute phase protein, our results indicated that changes in synthetic rates and changes in glycosylation induced in the acute phase response are regulated independently.

Key words: Transferrin - Glycosylation - Disease activity Acute phase response - Erythroblast iron availability

\section{Introduction}

Rheumatoid arthritis (RA) is often accompanied by anemia which can be of different origins [1,2]. Iron deficiency anemia $[3,4]$ and the anemia of chronic disease (ACD) [5] are frequently associated with active RA. Many studies have been carried out to elucidate the pathogenesis of $\mathrm{ACD}$ in RA. Concepts that have been postulated include inhibitory effects of cytokines on erythropoiesis [6-8] and a decreased erythropoietin responsiveness $[2,9]$. Other factors, such as impaired iron release by the mononuclear phagocyte system (MPS) [10-12] and decreased iron uptake and transferrin binding by erythroblasts [13], are thought to contribute to the genesis of $\mathrm{ACD}$ by reducing erythroblast iron availability.

Correspondence to: A. J. G. Swaak
Iron fluxes between different compartments are thought to rely predominantly on transport by transferrin [14]. Transferrin iron saturation, the affinity of transferrin for it receptor and the number of transferrin receptors expressed by erythroblasts determine erythroblast iron uptake in this scheme.

Being a glycoprotein with N-linked glycans, transferrin is subject to the phenomenon of microheterogeneity. This involves structural variation in the carbohydrate moiety of transferrin, which results in a limited number of transferrin isotypes that can be distinguished and quantitated electrophoretically [15]. Alterations in the relative proportions of the transferrin variants, reflecting changes in glycosylation, have been described in pregnancy and in several chronic diseases including RA, hemochromatosis and cancer $[15,16]$.

Current data on the microheterogeneity of transferrin suggest that functional properties of transferrin, such as the affinity to its receptor, can be modulated by this phenomenon $[14,17,18]$. This, in turn, may alter the biological activity of transferrin and could, therefore, influence iron delivery to target organs $[14,15,17,18]$.

In acute and chronic inflammatory conditions, increased synthesis of several positive acute phase glycoproteins (APG's) has been shown to be accompanied by changes in their microheterogeneity [19-23]. It is proposed that regulation of both synthesis and glycosylation of APG's is mediated by tumor necrosis factor alpha (TNF), interleukin-1 (IL-1), interleukin-6 (IL-6) and transforming growth factor $\beta 1$ [24-27].

In RA the existence of both ACD $[4,9]$ and alterations in the glycosylation pattern of a number of positive APG's appear to correlate with disease activity [22, 23], suggesting that changes in glycosylation are a direct consequence of an increase in the rate of synthesis of positive APG's. Transferrin is considered to be a negative acute phase protein [28]. Indeed, in RA patients with active RA and $A C D$ transferrin levels are decreased $[5,12]$.

The aim of this study was to assess the relation between the microheterogeneity pattern of transferrin and the serological disease activity in RA, since changes that 
are postulated to alter iron transport might be operative in ACD in RA.

\section{Patients and methods}

Patients. Serum was obtained from 21 healthy volunteers (controls) and from 25 patients with RA fitting the revised American Rheumatism Association (ARA) criteria [29]. Written informed consent was obtained from all subjects. The patients were divided into three groups. Group 1 comprised nine nonanemic patients with a mean $( \pm S D)$ age of $54 \pm 5$ years and a mean $( \pm S D)$ disease duration of $6 \pm 3$ years. Group 2 comprised seven patients with iron deficiency anemia based on the absence of stainable bone marrow iron. The patients in this group had a mean $( \pm S D)$ age of $56 \pm 5$ years and a mean $( \pm S D)$ disease duration of $6 \pm 3$ years. Group 3 comprised nine patients with ACD based on normal to increased bone marrow iron. The patients in group 3 had a mean $( \pm S D)$ of $59 \pm 7$ years and a mean $( \pm S D)$ disease duration of $8 \pm 4$ years. Mean age, sex and mean disease duration did not differ significantly between the three RA groups. All patients used nonsteroidal anti-inflammatory drugs, whereas $18(72 \%)$ were on long-acting antirheumatic drugs. Clinical disease activity was highest in group 3 and lowest in group 1.

Other causes of anemia were excluded by history-taking (present or past ulcer disease, other gastrointestinal disease or complaints, hypermenorrhoea and hematuria), by checking for stools negative for occult blood, a normal vitamin B12, folic acid, Coombs test, creatinine clearance and absence of microscopic hematuria.

The protocol for this study was accepted by the Medical Ethics Committee of the Dr. Daniel den Hoed Clinic.

Laboratory procedures. Erythrocyte parameters and disease activity were assessed as follows. Hemoglobin $(\mathrm{Hb})$, hematocrit $(\mathrm{Ht})$, reticulocytes, mean cell volume (MCV), serum iron, transferrin, ferritin and erythrocyte sedimentation rate (ESR) were measured using standard laboratory procedures. Iron saturation was determined by means of the ratio, serum iron/total iron binding capacity. C-reactive protein (CRP) was assessed by immunodiffusion techniques and C1q binding was measured by the method of Zubler and Lambert [30]. Bone marrow was aspirated after posterior iliac crest puncture and stained for iron using Perl's Prussian blue staining.

Assessment of transferrin microheterogeneity. Crossed immuno isoelectric focusing was carried out as described previously [15, 31]. Briefly, in the first phase transferrin subfractions were separated by isoelectric focusing on polyacrylamide gelstrips carrying an immobilized $\mathrm{pH}$-gradient. The second phase, which was run perpendicularly to the first, involved a rocket immunoelectrophoresis of all transferrin fractions simultaneously. This resulted in a pattern in which nine transferrin fractions were separated due to differences in sialic acid content; increased sialylation over four tesidues per molecule indicated increased branching of the glycans attached to the protein [15]. The relative proportions were ascertained by measurement of the areas enclosed by the immunoelectrophoretic peaks, and relative concentrations were derived from combining these data with total transferrin concentration, which had been determined by standard turbidemetric assay. In Fig. 1, examples are shown of a normal microheterogeneity pattern and of a pattern obtained from a RA patient with ACD.

Data obtained were divided into three subgroups: the low sialylated transferrin fractions (LSTf; the sum of 0-, 1-, 2- and 3-sialotransferrin), the 4-sialotransferrin fraction (4-STf; this is the predominant fraction in normal serum) and the highly sialylated transferrin fractions (HSTf; the sum of 5- to 8-sialotransferrin). This simplied classification was based on earlier observations that within these three groups, changes occuring in the relative amounts of transferrin fractions display similar trends [15], allowing for this simplification of presentation. All microheterogeneity patterns were assessed in duplicate.

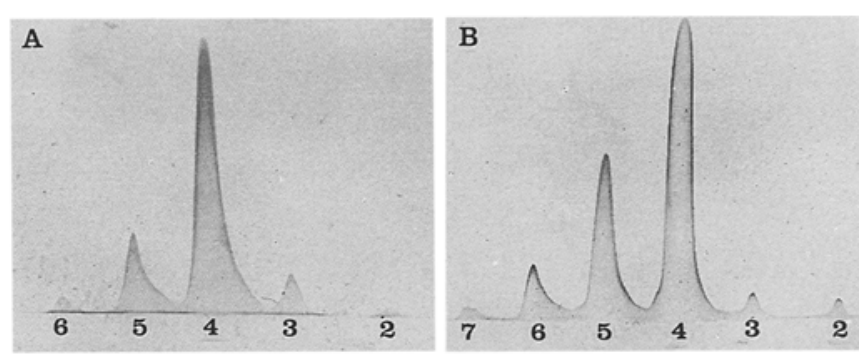

Fig. 1A, B. Transferrin microheterogeneity patterns analyzed by crossed immuno isoelectric focusing. A Healthy individual; $\mathbf{B}$ rheumatoid arthritis associated with the anemia of chronic disease. The indices beneath the patterns indicate the number of sialic acids attached to the $\mathrm{N}$-linked glycans of corresponding subfractions

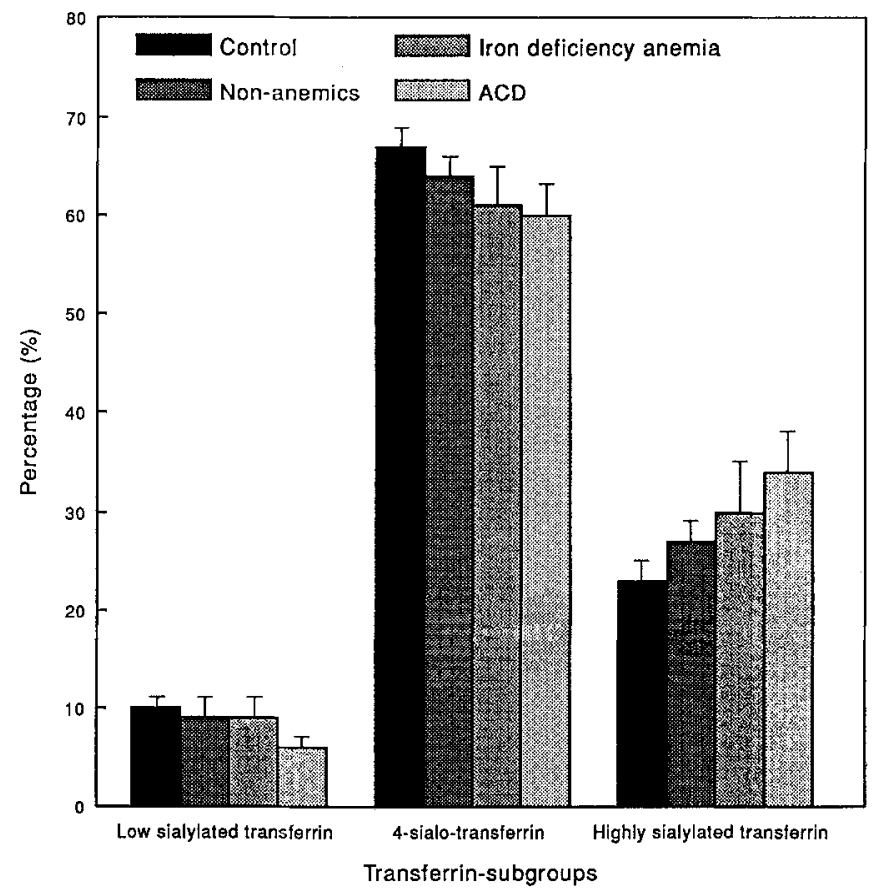

Fig. 2. Percentage distribution of the transferrin subfractions in controls, group 1 (RA-nonanemics), group 2 (RA-iron deficiency anemia) and group 3 (RA-anemia of chronic disease)

Statistical analysis. Normally distributed data were compared using Student's $t$-test and non-parametric data by the Mann-Whitney $U$-test. Coefficients of correlation were calculated using Spearman's test.

\section{Results}

\section{Iron status and RA-disease activity}

Patient characteristics are shown in Table 1. In comparison with group 1 (nonanemic patients) transferrin was significantly lower in group $3(A C D)$ and significantly elevated in group 2 (iron deficiency anemia). In all groups, however, transferrin was lower than in controls (mean $38.2 \mu \mathrm{mol} / \mathrm{l}$ ). Total transferrin concentration correlated with ESR $(r=0.55, P<0.01)$ and CRP $(r=-0.48$, $P<0.05$ ) in group 1 and group 3. 
Table 1 a, b. Patient characteristics in groups 1,2 and 3. a Erythrocyte variables and iron status. $\mathbf{b}$ Parameters of disease activity. Data are expressed as median with range

\begin{tabular}{|c|c|c|c|}
\hline & Group 1 & Group 2 & Group 3 \\
\hline \multicolumn{4}{|c|}{$\begin{array}{l}\text { a } \\
\text { Erythrocyte parameters }\end{array}$} \\
\hline $\begin{array}{l}\mathrm{Hb}(\mathrm{mmol} / \mathrm{l}) \\
(7.4-10.9)\end{array}$ & $\begin{array}{l}8.0 \\
(7.7-8.7)\end{array}$ & $\begin{array}{l}6.5 \\
(4.3-7.1)\end{array}$ & $\begin{array}{l}6.6 \\
(5.7-6.9)\end{array}$ \\
\hline $\begin{array}{l}\text { Ht }(1 / 1) \\
(0.36-0.51)\end{array}$ & $\begin{array}{l}0.39 \\
(0.35-0.42)\end{array}$ & $\begin{array}{l}0.34 \\
(0.24-0.37)\end{array}$ & $\begin{array}{l}0.31 \\
(0.28-0.35)\end{array}$ \\
\hline $\begin{array}{l}\mathrm{MCV}(\mathrm{fl}) \\
(80-96)\end{array}$ & $\begin{array}{l}88 \\
(80-116)\end{array}$ & $\begin{array}{l}85 \\
(61-95)\end{array}$ & $\begin{array}{l}87 \\
(80-98)\end{array}$ \\
\hline Reticulocytes $(0 / 00)$ & $\begin{array}{l}13 \\
(1-39)\end{array}$ & $\begin{array}{l}11 \\
(5-26)\end{array}$ & $\begin{array}{l}17 \\
(1-30)\end{array}$ \\
\hline \multicolumn{4}{|l|}{ Iron status } \\
\hline $\begin{array}{l}\text { Iron }(\mu \mathrm{mol} / 1) \\
(14-30)\end{array}$ & $\begin{array}{l}6 \\
(1-11)\end{array}$ & $\begin{array}{l}6 \\
(2-10)\end{array}$ & $\begin{array}{l}4 \\
(2-17)\end{array}$ \\
\hline $\begin{array}{l}\text { Transferrin } \\
(25-55 \mu \mathrm{mol} / 1)\end{array}$ & $\begin{array}{l}28 \\
(20-39)\end{array}$ & $\begin{array}{l}32 * \\
(26-41)\end{array}$ & $\begin{array}{c}23 * * \\
(18-32)\end{array}$ \\
\hline $\begin{array}{l}\text { Iron saturation } \\
(\%)\end{array}$ & $\begin{array}{l}12 \\
(2-23)\end{array}$ & $\begin{array}{l}11 \\
(4-15)\end{array}$ & $\begin{array}{l}9 \\
(4-27)\end{array}$ \\
\hline $\begin{array}{l}\text { Ferritin }(\mu \mathrm{g} / \mathrm{l}) \\
(20-150)\end{array}$ & $\begin{array}{l}50 \\
(10-326)\end{array}$ & $\begin{array}{c}10 * * \\
(10-53)\end{array}$ & $\begin{array}{l}125 * * * \\
(89-432)\end{array}$ \\
\hline \multicolumn{4}{|l|}{$\begin{array}{l}\text { b } \\
\text { Disease activity }\end{array}$} \\
\hline $\begin{array}{l}\operatorname{ESR}(\mathrm{mm} / \mathrm{l}) \\
(<10)\end{array}$ & $\begin{array}{l}36 \\
(21-65)\end{array}$ & $\begin{array}{l}57 * \\
(32-70)\end{array}$ & $\begin{array}{l}87 * * * \\
(52-105)\end{array}$ \\
\hline $\begin{array}{l}\text { CRP (mg/l) } \\
(<6)\end{array}$ & $\begin{array}{l}23 \\
(2-54)\end{array}$ & $\begin{array}{l}20 \\
(2-78)\end{array}$ & $\begin{array}{l}35^{* *} \\
(11-121)\end{array}$ \\
\hline $\begin{array}{l}\text { C1qba }(\%) \\
(<7)\end{array}$ & $\begin{array}{l}8 \\
(3-32)\end{array}$ & $\begin{array}{l}19 \\
(3-78)\end{array}$ & $\begin{array}{l}25 * * \\
(5-75)\end{array}$ \\
\hline
\end{tabular}

$* P<0.10 ; * * P<0.05 ; * * * P<0.01$, data compared to the nonanemic group

Table 2. Relation between percentages of transferrin subfractions and disease activity and hemoglobin. $\%$ LSTf $=\%$ low sialylated transferrin fractions; $\%$ 4-STf $=\%$ 4-sialotransferrin; $\% \mathrm{HSTf}=\%$ highly sialylated transferrin fractions; NS= not significant

\begin{tabular}{llll}
\hline & \% LSTf & $\%$ 4-STf & $\%$ HSTf \\
\hline ESR & $r=-0.73$ & $r=-0.52$ & $r=0.74$ \\
& $(P<0.0005)$ & $(P<0.025)$ & $(P<0.0005)$ \\
CRP & $r=-0.61$ & $r=-0.29$ & $r=0.49$ \\
& $(P<0.005)$ & $(\mathrm{N} . \mathrm{S})$. & $(P<0.025)$ \\
C1qba & $r=-0.87$ & $r=-0.55$ & $r=0.75$ \\
& $(P<0.005)$ & $(P<0.05)$ & $(P<0.01)$ \\
Hb & $r=0.69$ & $r=0.50$ & $r=-0.69$ \\
& $(P<0.005)$ & $(P<0.025)$ & $(P<0.005)$ \\
\hline
\end{tabular}

The ferritin level was significantly elevated in group 3 and significantly decreased in group 2 compared to group 1 . The values of the iron status in the control group were within the normal range.

Disease activity, as assessed by ESR (although it is known that ESR and $\mathrm{Ht}$ correlate negatively to some extent), CRP and $\mathrm{C}_{1}$ qba was highest in group 3 , intermediate in group 1 and lowest in group 1.
Transferrin microheterogeneity

A shift in transferrin microheterogeneity was evident in all RA groups (see Fig. 2). This change was characterized by a significant increase in the percentage of highly sialylated transferrin fractions ( $\%$ HSTf $)(P<0.01)$ and a significant decrease of the percentage of 4-sialotransferrin $(\%$ 4-STf; $P<0.01)$. The percentage of low sialylated transferrin fractions (\% LSTf) was decreased in all groups, but only significantly in group $3(P<0.01)$.

Compared with group 1 , the $\%$ HSTf was significantly higher $(P<0.01)$ and the \% 4-STf ws significantly lower in group $3(P<0.05)$. The \% LSTf was significantly lower in group $3(P<0.01)$ compared to both groups 2 and group 1. These results showed that the shift to highly branched glycan chains exhibits the same pattern in all RA groups as the degree of disease activity. The shift was most pronounced in group 3, intermediate in group 2 and least pronounced in group 1.

Table 2 shows that an increased inflammatory activity was associated with an increased \% HSTf and a decreased \% 4-STf and \% LSTf. An inverse relation was shown between the \% HSTf and $\mathrm{Hb}$, whereas the \% 4-STf and \% LSTf correlated positively with $\mathrm{Hb}$.

\section{Discussion}

The aim of this study was to assess transferrin microheterogeneity in RA and to relate this to disease activity. Our results showed that increasing disease activity was associated with preferential synthesis of transferrin variants with highly branched glycan chains. Since the degree of inflammatory activity was highest in ACD, the shift in transferrin microheterogeneity was most pronounced in this group.

It has been shown that qualitative changes in the glycosylation of glycoproteins can be accompanied by changes in their functional properties [21, 32-34]. During pregnancy, an increment of the highly sialylated transferrin fractions is thought to serve a functional purpose since it coincides with the increase in iron fluxes to both the placenta and the maternal bone marrow $[14,15,17]$. Recent work demonstrated that highly sialylated transferrins have a higher affinity for the transferrin receptor expressed at the maternal side of the placenta (de Jong et al., manuscript in preparation). This receptor is identical to the transferrin receptor isolated from reticulocytes, with respect to molecular size and immunoreactivity [35]. The high correlation between changes in transferrin microheterogeneity and disease activity suggests that the changes in glycosylation are of functional significance. The increased synthesis of highly sialylated transferrin fractions in the face of both the impaired erythroblast iron availability in ACD and the counteractive decrease in total transferrin protein synthesis may, therefore, be viewed as part of the compensatory mechanism attempting to facilitate iron transport to erythroblasts. In accordance with this proposal is the relation between the preferential synthesis of highly sialylated transferrins and the decrease in $\mathrm{Hb}$. Despite this possible compensation, ery- 
thropoiesis remains impaired; this may be related to inhibitory effects of cytokines. TNF and IL-1 suppress erythroid colony growth in vitro and their serum levels are increased in active RA [6, 36-39]. Thus, the inhibited erythroblast iron uptake, which has been shown to accompany the diminished erythropoiesis in ACD [13] might be attributed to increased levels of TNF and IL-1.

Alternatively, the decreased iron incorporation by erythroblasts may be related to an impaired erythropoietin (EPO) responsiveness, thought to be present in ACD in $\mathrm{RA}[2,9]$, since EPO is able to increase transferrin receptor expression by erythroblasts [40] with a concomitant facilitation of iron uptake. An interesting observation in this respect is that treatment of RA patients with ACD with recombinant human erythropoietin (r-Hu-EPO) is accompanied by an increase in serum soluble transferrin receptor (sTfR) levels [41]. It has been shown that sTfR levels correlate with tissue TfR levels and that higher sTfR levels may reflect iron deficiency [42-44]. The increase in sTfR levels during r-Hu-EPO therapy might, therefore, indicate an increased erythropoiesis accompanied by a decrease in body iron stores based on increased iron mobilization and iron utilization [41]. Assuming a role for transferrin microheterogeneity in the fine-tuning of iron fluxes, it might be speculated that alterations in the glycosylation pattern of transferrin are associated with changes in sTfR levels.

The fact that transferrin is a negative acute phase protein facilitates a second conclusion from the observed shift in microheterogeneity. One of the main characteristics of the acute phase response is the change in the rates of synthesis of plasma glycoproteins [28]. In addition, concomitant alterations are induced in the glycosylation of various positive acute phase glycoproteins (APGs) [19-21]. In RA for instance, the changes in the carbohydrate moieties of alpha- ${ }_{1}$-acid glycoprotein and haptoglobin, both positive APGs, are related to the degree of inflammatory activity $[22,23]$. It has been shown for numerous glycoproteins, including transferrin, that changes in the carbohydrate moiety are a concomitant feature of increased synthesis, and a linkage between the regulation of gene expression and glycosylation, has been suggested $[14,19]$. Our study showed that in active RA posttranslational modification is directed towards increased synthesis of transferrin carrying highly branched glycans, under conditions where translation of the gene has diminished. This indicated that in the acute phase response, although an altered clearance of the various transferrin isotypes cannot be excluded, these processes are regulated by different mechanisms. This is supported by the observed dissociation between the mechanisms that regulate the synthesis of alpha-fetoprotein and $\alpha_{1}$ protease inhibitor and their glycosylation $[24,45]$.

In the acute phase response, changes in both rate of synthesis and carbohydrate moieties of positive APG's are thought to be mediated by cytokines [24-27]. Both TNF and IL-6 exert a negative influence on transferrin synthesis in vitro [26, 46], whereas it is not known whether these cytokines affect the glycosylation of transferrin. Transferrin levels in the three RA groups were lower than in controls and the inverse relation between transferrin and parameters of disease activity confirmed the fact that transferrin is a negative APG. In active RA, TNF and IL-6 levels are elevated and correlate with disease activity $[8,39,47]$. This suggests that TNF and IL-6 might inhibit the synthesis of transferrin in active RA and possibly influence its glycosylation pattern.

In conclusion, our study showed that in RA the induction of both ACD and the shift in transferrin microheterogeneity was related to increased disease activity. As a response to counter-reproductive effects, such as the impaired erythroblast iron uptake and the decrease in transferrin concentration, preferential synthesis of highly sialylated transferrin variants in ACD may serve as a compensatory mechanism to improve erythroblast iron availability.

\section{References}

1. Mowat AG (1971) Hematologic abnormalities in rheumatoid arthritis. Arthritis Rheum 1:383-390

2. Vreugdenhil G, Wognum AW, Eijk HG van, Swaak AJG (1990) Anemia in rheumatoid arthritis. The role of iron, vitamin B12 and folic acid deficiency and erythropoietin responsiveness. Ann Rheum Dis 49:93-98

3. Hansen TM, Hansen NE, Birgens HS, Hølund B, Lorenzen I (1983) Serum ferritin and the assessment of iron deficiency in rheumatoid arthritis. Scand J Rheumatol 12:353-359

4. Vreugdenhil G, Baltus CAM, Eijk HG van, Swaak AJG (1990) Anemia of chronic disease: diagnostic significance of erythrocyte and serological parameters in iron deficient rheumatoid arthritis patients. Br J Rheumatol 29:105-110

5. Cartwright GE, Lee GR (1971) The anemia of chronic disorders. Br J Haematol 21:147-152

6. Maury CPJ, Andersson LC, Teppo AM, Partanen S, Juvonen $E$ (1988) Mechanisms of anemia in rheumatoid arthritis: demonstration of raised interleukine- $1 \beta$ concentrations in anemic patients and of interleukine-1 mediated suppression of normal erythropoiesis and proliferation of human erythroleukemia (H.E.L.) cells in vitro. Ann Rheum Dis 47:972-987

7. Roodman GD (1987) Mechanisms of erythroid suppression in the anemia of chronic disease. Blood Cells 13:171-184

8. Vreugdenhil G, Löwenberg B, Eijk HG van, Swaak AJG (1990) Anemia of chronic disease in rheumatoid arthritis: raised serum interleukine-6 (IL-6) levels and effects of IL- 6 and anti-IL-6 on in vitro erythropoiesis. Rheumatol Int 10:127-130

9. Birgegard $G$, Hällgran R, Caro J (1987) Serum erythropoietin in rheumatoid arthritis and other inflammatory athritides: relationship to anemia and the effect of anti-inflammatory treatment. Br J Haematol 65:479-483

10. Beamish MR, Davis AG, Eakins JD, Jacobs A (1971) The measurement of reticuloendothelial iron release using iron dextran. Br J Haematol 21:617-622

11. Bentley DP, Cavill I, Rickets C, Peake S (1979) A method for the investigation of reticuloendothelial iron kinetics in man. $\mathrm{Br}$ J Haematol 43:619-624

12. Vreugdenhil G, Swaak AJG (1990) Anaemia in rheumatoid arthritis: pathogenesis, diagnosis and treatment. Rheumatol Int 9: $243-257$

13. Vreugdenhil G, Kroos MJ, Eijk HG van, Swaak AJG (1990) Impaired iron uptake and transferrin binding by erythroblasts in the anaemia of rheumatoid arthritis. $\mathrm{Br} \mathrm{J}$ Rheumatol 29: $335-339$

14. Jong G de, Dijk JP van, Eijk HG van (1990) The biology of transferrin. Clin Chim Acta 190:1-46

15. Jong $G$ de, Eijk HG van (1988) Microheterogeneity of human transferrin, a biological phenomenon studied by isoelectric 
focusing in immobilized $\mathrm{pH}$ gradients. Electrophoresis 9: $589-$ 598

16. Eijk HG van, Noort WL van, Jong G de, Koster JF (1987) Human serum sialo transferrins in diseases. Clin Chim Acta 165: $141-145$

17. Jong $G$ van, Eijk $H G$ van (1989) Functional properties of the carbohydrate moiety of human transferrin. Int $\mathrm{J}$ Biochem 21:253-263

18. Bezouška K, Táborský $\mathrm{O}$, Kubrycht J, Pospišil M, Kocourek J (1985) Carbohydrate-structure-dependent recognition of desialylated serum glycoproteins in the liver and leukocytes. Biochem J 227:345-354

19. Raynes $J(1982)$ Variations in the relative proportions of microheterogeneous forms of plasma glycoproteins in pregnancy and disease. Biomedicine 36:77-86

20. Mackiewicz A, Marcinkowska-Pieta R, Ballou S, Mackiewicz S, Kushner I (1987) Microheterogeneity of alpha-1-acid glycoprotein in the detection of intercurrent infection in systemic lupus erythematosus. Arthritis Rheum 30:513-518

21. Lejeune PJ, Mallet B, Farnarier C, Kaplanski S (1989) Changes in the serum level and affinity for concanavalin $A$ of human alpha-1-proteinase inhibitor in severe burn patients: relationship to natural killer cell activity. Biochim Biophys Acta 990: $122-127$

22. Mackiewicz A, Pawlowski T, Mackiewicz-Pawlowska A, Wiktorowicz K, Mackiewicz S (1987) Microheterogeneity forms of alpha-1-acid glycoprotein as indicators of rheumatoid arthritis activity. Clin Chim Acta 163:185-190

23. Thompson S, Kelly CA, Griffiths ID, Turner GA (1989) Abnormally-fucosylated serum haptoglobins in patients with inflammatory joint disease. Clin Chim Acta 184:251-258

24. Mackiewicz A, Kushner I (1990) Transforming growth factor $\beta 1$ influences glycosylation of $\alpha 1$-protease inhibitor in human hepatoma cell lines. Inflammation 5:485-497

25. Ramadori $G$, Damme J van, Rieder $H$, Meyer zum Büschenfelde KH (1988) Interleukin 6, the third mediator of acutephase reaction, modulates hepatic protein synthesis in human and mouse. Comparison with interleukin $1 \beta$ and tumor necrosis factor $\alpha$. Eur J Immunol 18:1259-1264

26. Perlmutter DH, Dinarello CA, Punsal PI, Colten HR (1986) Cachetin/tumor necrosis factor regulates hepatic acute-phase gene expression. J Clin Invest 78:1349-1354

27. Pos O, Moshage HJ, Yap SH, Snieders JPM, Aarden LA, van Gool J, Boers W, Brugman AM, Dijk W van (1989) Effects of monocytic products, recombinant interleukin-1 and recombinant interleukin-6 on glycosylation of alpha-1-acid glycoprotein: studies with primary human hepatocyte cultures and rats. Inflammation 13:415-427

28. Kushner I (1982) The phenomenon of the acute phase response. Ann NY Acad Sci 389: 39-48

29. Arnett FC, Edworthy SM, Bloch DA et al (1988) The American Rheumatism Association 1987. Revised criteria for the classification of rheumatoid arthritis. Arthritis Rheum 31:315-324

30. Zubler RH, Lambert DH (1977) ${ }^{125} \mathrm{I} \mathrm{C1}$ q binding test for soluble immune complexes. Ann Rheum Dis 36:27-30

31. Noort WL van, Eijk HG van (1987) Quantitation of subfractions of serum transferrins using crossed immunofocusing with Immobiline gels. Sci Tools 34:1-3

32. Dubé S, Fischer JW, Powell JS (1988) Glycosylation at specific sites of erythropoietin is essential for biosynthesis, secretion and biological function. J Biol Chem 263:17516-17521
33. Avvakumov GV, Stel'chyonok OA (1987) Evidence for the involvement of the transcortin carbohydrate moiety in the glycoprotein interaction with plasma membrane of human placenta syncytiotrophoblast. Biochim Biophys Acta 93:1-6

34. Pos O, Oostendorp RA, Stelt ME van der, Scheper RJ, Dijk W van (1990) Con A-nonreactive human alpha 1-acid glycoprotein (AGP) is more effective in modulation of lymphocyte proliferation than Con A-reactive AGP serum variants. Inflammation 14:133-141

35. Enns CA, Sussman HH (1981) Similarities between the transferrin receptor proteins on human reticulocytes and human placentae. J Biol Chem 256:12620-12623

36. Schooley JC, Kullgren B, Allison AC (1987) Inhibition by interleukin-1 of the action of erythropoietin on erythroid precursors and its possible role in the pathogenesis of hypoplastic anaemias. $\mathrm{Br} \mathrm{J}$ Haematol 67:11-17

37. Lu L, Welte K, Gabrilove JL, Hangoc G, Bruno E, Hoffman R, Broxmeyer HE (1986) Effects of recombinant tumor necrosis factor alpha, recombinant human gamma-interferon, and prostaglandin $\mathrm{E}$ on colony formation of human hematopoietic progenitor cells stimulated by natural human pluripotent colony stimulating factor, pluripoietin alpha, and recombinant erythropoietin in serum-free cultures. Cancer Res 46:43574361

38. Malkovský M, Sondel PM, Strober W, Dalgleish AG (1988) The interleukins in acquired disease. Clin Exp Immunol 74:151-161

39. Saxne T, Palladino MA Jr, Heinegard D, Tala1 N, Wollheim FA (1988) Detection of tumor necrosis factor alpha but not tumor necrosis factor beta in rheumatoid arthritis synovial fluid and serum. Arthritis Rheum 31:1041-1045

40. Sawyer ST, Krantz SB (1988) Transferrin receptor number, synthesis and endocytosis during erythropoietin-induced maturation of Friend virus-infected erythroid cells. J Biol Chem 261:9187-9195

41. Vreugdenhil G, Manger B, Nieuwenhuizen C, Eijk HG van, Swaak AJG (1992) Iron stores and serum transferrin receptor levels during recombinant human erythropoietin treatment of anemia in rheumatoid arthritis. Ann Haematol 65: (in press)

42. Baynes RD, Shih YJ, Cook JD (1991) Production of soluble transferrin receptor by K562 erythroleukemia cells. Br J Haematol 78: 450-455

43. Kohgo Y, Nishisato T, Kondo H, Tsushima N, Niitsu Y, Urushshizaki I (1986) Circulating transferrin receptor in human serum. Br J Haematol 64:277-281

44. Skikne BS, Flowers C, Cook JD (1990) Serum transferrin receptor: A quantitative measure of tissue iron deficiency. Blood 75: $1870-1876$

45. Mackiewicz A, Kushner I (1989) Interferon $\beta 2 / \mathrm{B}$-cell stimulating factor $2 /$ interleukin 6 affects glycosylation of acute phase proteins in human hepatoma cell lines. Scand J Immunol 29:265-271

46. Castell JV, Gómez-Lechón MJ, David M, Andus T, Geiger T, Trullenque R, Fabra R, Heinrich PC (1989) Interleukin-6 is the major regulator of acute phase protein synthesis in adult human hepatocytes. FEBS Lett 242:237-239

47. Swaak AJG, Rooyen A van, Nieuwenhuis E, Aarden LA (1988) Interleukin-6 (IL-6) in synovial fluid and serum of patients with rheumatic diseases. Scand J Rheumatol 17:469-474 